\title{
BMJ Open Community perceptions on demand- side incentives to promote institutional delivery in Oyam district, Uganda: a qualitative study
}

\author{
William Massavon, ${ }^{1}$ Calistus Wilunda, ${ }^{\oplus, 3}$ Maria Nannini, ${ }^{4}$ Caroline Agaro, ${ }^{5}$ \\ Simon Amandi, ${ }^{5}$ John Bosco Orech, ${ }^{5}$ Emanuela De Vivo, ${ }^{1}$ Peter Lochoro, ${ }^{6}$ \\ Giovanni Putoto 7
}

To cite: Massavon W,

Wilunda C, Nannini M, et al. Community perceptions on demand-side incentives to promote institutional delivery in Oyam district, Uganda: a qualitative study. BMJ Open 2019;9:e026851. doi:10.1136/ bmjopen-2018-026851

- Prepublication history and additional material for this paper are available online. To view these files, please visit the journal online (http://dx.doi org/10.1136/bmjopen-2018026851).

Received 22 September 2018 Revised 19 July 2019 Accepted 05 August 2019
Check for updates

(C) Author(s) (or their employer(s)) 2019. Re-use permitted under CC BY-NC. No commercial re-use. See rights and permissions. Published by BMJ.

For numbered affiliations see end of article.

Correspondence to Dr Calistus Wilunda; calistuswilunda@yahoo.co.uk

\section{ABSTRACT}

Objective To examine the perceptions of community members and other stakeholders on the use of baby kits and transport vouchers to improve the utilisation of childbirth services.

Design A qualitative study.

Setting Oyam district, Uganda.

Participants We conducted 10 focus group discussions with 59 women and 55 men, and 18 key informant interviews with local leaders, village health team members, health facility staff and district health management team members. We analysed the data using qualitative content analysis.

Results Five broad themes emerged: (1) context, (2) community support for the interventions, (3) healthseeking behaviours postintervention, (4) undesirable effects of the interventions and (5) implementation issues and lessons learnt. Context regarded perceived long distances to health facilities and high transport costs. Regarding community support for the interventions, the schemes were perceived to be acceptable and helpful particularly to the most vulnerable. Transport vouchers were preferred over baby kits, although both interventions were perceived to be necessary. Health-seeking behaviours entailed perceived increased utilisation of maternal health services and 'bypassing', promotion of collaboration between traditional birth attendants and formal health workers, stimulation of men's involvement in maternal health, and increased community awareness of maternal health. Undesirable effects of the interventions included increased workload for health workers, sustainability concerns and perceived encouragement to reproduce and dependency. Implementation issues included information gaps leading to confusion, mistrust and discontent, transport voucher scheme design; implementation; and payment problems, poor attitude of some health workers and poor quality of care, insecurity, and a shortage of baby kits. Community involvement was key to solving the challenges.

Conclusions The study provides further insights into the implementation of incentive schemes to improve maternal health services utilisation. The findings are relevant for planning and implementing similar schemes in lowincome countries.
Strengths and limitations of this study

- We collected data from a wide variety of respondents to ensure a cross-sectional representation of viewpoints.

- Triangulation of the results from different categories of respondents and data collection methods increases the validity of our findings.

- Most key informants were male, which might have led to biases in some of the perceptions elicited.

- The venues for focus group discussions might have limited the freedom of expression for some participants.

\section{INTRODUCTION}

Despite decades of implementing interventions to improve maternal health outcomes, complex and multifaceted barriers still impede progress to achieve set targets in many low-income and middle-income countries, particularly in sub-Saharan Africa (SSA). ${ }^{1}$ This situation contributed significantly to the largely unachieved Millennium Development Goals 4 and 5 in the region. ${ }^{2}$ Numerous barriers to obstetric care still exist in SSA, translating into huge coverage gaps, particularly for services that require regular contacts with the health system. ${ }^{2}$ For instance, in 2016, the coverage of at least four antenatal care (ANC) visits in SSA was 52\% compared with the global average of $60 \%$, and that of delivery by a skilled birth attendant was about $50 \%$ compared with the global average of $78 \%$. $^{3}$ These average statistics, however, mask stark inequities defined by region, wealth status and urban/rural place of residence. ${ }^{2-4}$

In the quest for practical solutions, several studies on incentive schemes targeting barriers to utilisation of maternal health services have shown positive results. ${ }^{5-9}$ However, there is a need for context-sensitive 
approaches. As illustrations, a study in Kenya reported that some women who purchased service vouchers meant to cover direct healthcare costs did not use them because of high transport costs, which were not considered during the study design. ${ }^{10}$ A recent study in South Sudan found that women continued to deliver at home despite the availability of free-of-charge delivery services in their county. $^{11}$

Interventions designed with inputs from the beneficiary communities are more likely to succeed. Early dialogues involving beneficiary communities before and during the design and implementation of interventions may identify and prioritise the needs of the communities, explore and address potential barriers, and promote community engagement, which may generate a sense of ownership among the beneficiaries. ${ }^{12-14}$

Incentive schemes have become popular in Uganda, with promising results. A recent study has shown that offering Maama kits to pregnant women during facility delivery was associated with perceptions of affordable healthcare. However, logistical challenges and inconsistent implementation could undermine the desired outcomes of the intervention. ${ }^{15}$ Another study has shown that maternal health vouchers have the potential to increase coverage of services through several pathways, such as strengthening public-private partnerships, which in turn can enhance referral networks and shorten distances to service points for potential users. ${ }^{16}$

Oyam district has almost 390000 inhabitants ${ }^{17}$ and is situated in a rural postconflict region in northern Uganda. The district has high levels of illiteracy, poverty and fertility, but a low family planning uptake. In 2016, $42 \%$ of women delivered in a health facility according to routine data, whereas the region-wide (Lango) contraceptive prevalence rate was $41 \%$ according to a household survey. ${ }^{18}$ Most of its residents live more than $5 \mathrm{~km}$ away from a health facility. The health system is weak and relies on regular support from donors/partners to provide basic services. Moreover, the majority of the health facilities are health centre (HC) level 2 with limited capacity to provide maternity services. ${ }^{19}$ Consequently, some residents have to travel long distances to access higher quality healthcare. Some pregnant women are compelled to use nearby health facilities that may be providing low-quality maternity services or to deliver at home without skilled care. $^{20-22}$

Considering the barriers to accessing health services in Oyam District, in 2014, Doctors with Africa Collegio Universitario Aspiranti e Medici Missionari (CUAMM), hereafter referred to as CUAMM, implemented two demand-side incentive schemes-baby kits and transport vouchers-to improve the utilisation of institutional delivery services. A study on the effects of the interventions has been published. ${ }^{23}$ The present study examines the perceptions of the community members and other stakeholders on those incentive schemes.
MATERIALS AND METHODS

\section{Design}

This qualitative study collected data using focus group discussions (FGDs) and key informant interviews (KIIs). FGDs were used to explore the general perceptions of community members whereas KIIs were used to gather in-depth information from other stakeholders and to triangulate some of the information gathered through FGDs. Data were analysed using qualitative content analysis approach, which is an efficient method to analyse a large volume of textual data, yielding a condensed and broad description of phenomenon inform of structured concepts or categories. ${ }^{24}$ We report this study according to the consolidated criteria for reporting qualitative research. $^{25}$

\section{Setting}

This study was conducted in four subcounties in Oyam district, where baby kit and transport voucher schemes were implemented by CUAMM. Details about the setting, the selection of the subcounties and the incentive schemes have been described elsewhere. ${ }^{23}$ In brief, two subcounties with the lowest institutional delivery coverages in the district were purposively selected after consultations with local authorities. Community dialogues played a crucial role in the design, implementation and improvement of the interventions. The dialogues were open gatherings involving local community leaders, members of the village health teams (VHT), social workers, the research team, the project staff of CUAMM and other stakeholders. The meetings also availed an opportunity to provide feedback to the community on the interventions and to highlight the challenges that needed solutions from the community. The discussions yielded suggestions to improve the interventions, particularly the transport voucher system, and to phase out the baby kits.

Transport vouchers were given to pregnant women attending ANC and/or delivering in one of the study subcounties. The vouchers were meant to improve geographical accessibility to health facilities. In the second study subcounty, baby kits were offered to all pregnant women who delivered at the only health facility in that subcounty. The baby kits were meant to encourage facility delivery while easing the cost of newborn care. Each baby kit consisted of a plastic basin, a bar of soap, a polythene bag, $1 / 2 \mathrm{~kg}$ of sugar, and a piece of cotton cloth for wrapping the baby. Each voucher was valued at US $\$ 4 .^{23}$ Two comparable subcounties were selected as controls. ${ }^{23}$ Based on the findings, we extended the transport vouchers to the two control subcounties in 2016 for 3 more years, whereas, the baby kits were phased out. Thus, the interventions were ongoing at the time of this study.

\section{Participants and sampling}

Participants of FGDs consisted of women who used maternal health services in 2015/2016 and their male partners. These participants were purposively selected through multiple approaches, including face-to-face 
invitations with the help of VHT members, phone calls and invitation letters. Participants of KIIs were identified through snow-balling and consisted of people considered to be knowledgeable about maternal health service delivery in the study subcounties or district. They included subcounty chiefs, midwives, health facility in-charges, a politician, VHT focal persons, and members of the district health management team (DHMT). There were no refusals or drop-outs during the study.

\section{Data collection}

Data were collected in 2015/2016 using pretested and refined open-ended interview guides (online supplementary file 1) by a team of research assistants trained on how to facilitate FGDs. The FGD data collection team consisted of a moderator, a translator, a note-taker-all conversant with the local language and culture-and two of the investigators ( $\mathrm{WM}$ and $\mathrm{MN}$ ). The investigators supervised data collection and followed the discussions through the translator. WM and MN conducted all KIIs in English. For technical challenges, 8 out of 10 FGDs and 16 out of 18 interview sessions were audio recorded and field notes were taken for the rest. FGDs lasted 90-120 min while the KIIs lasted $30-40 \mathrm{~min} .{ }^{26}$ There were no repeat interviews. Data saturation was achieved when participants had nothing more to say on probes from the data collectors. We were unable to return transcripts to participants for comments due to logistical challenges.

Data were collected at locations that were considered most convenient by the participants. As most participants of the FGDs were from distant villages, data were collected at HCs. Only one of the men's FGDs was conducted at a trading centre proposed by the participants. At the HCs, a room was allocated to the research team and the discussions and interviews were conducted behind closed doors. Since the venues were reserved for the exclusive use by the research team on the selected days, there were no interruptions from intruders including health facility staff. The FGD at the trading centre was also conducted in a venue that ensured privacy. Similarly, KIIs with facility in-charges, midwives, and VHT members were conducted at HCs. Other key informants were interviewed in their respective offices.

This study included 10 FGDs (5 for each gender) consisting of 114 participants, and 18 KIIs (figure 1). Twelve of the key informants were male.

\section{Data analysis}

All the audio-recorded interviews and FGDs were transcribed verbatim and translated into English, where applicable, by a professional translator. Field notes, all taken in English, were edited at the end of each day of data collection and typed into a Word document. The transcripts were then cross-checked with the field notes. Data were coded by two of the authors (WM and CW) using NVivo V.11 (QSR International, Melbourne, Australia). Qualitative content analysis approach suggested by Gläser and Laudel $^{27}$ was used. This approach, which is arguably more

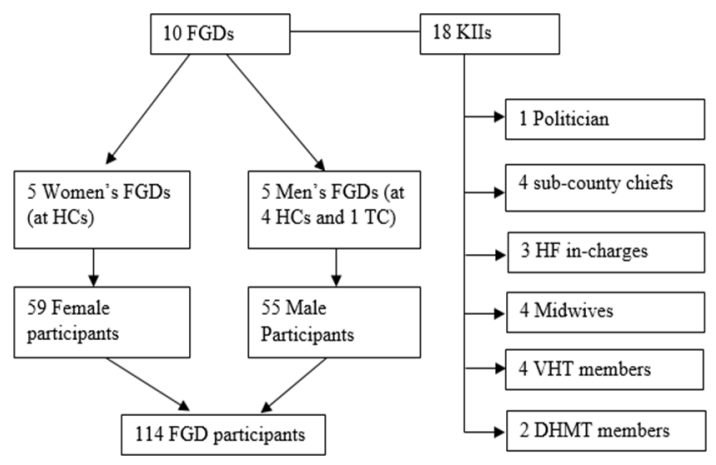

Figure 1 The number of participants in focus group discussions and key informant interviews. DHMT, district health management team; FGDs, focus group discussions; HCs, health centres; HF, health facility; KIls, key informant interviews; TC, trading centre; VHTs, village health teams.

efficient and open than other alternatives, ${ }^{27}$ involved reading through transcripts and field notes several times to identify emerging themes, setting up a list of the preidentified themes in NVivo, coding segments of the text that corresponded to the theme, and updating the list as new themes emerged during coding. Differences between the coders were resolved by consensus. After completing the coding process, segments of text under each theme were then summarised to provide an overview of the content relating to that specific theme. Related themes were categorised into broader themes. We performed triangulation of data sources and methods by comparing information from different sources (categories of respondents) and different data collection methods (KIIs and FGDs). We captured quotations from the participants to illustrate typical responses.

All participants provided written informed consent. For illiterate participants, this was done in the presence of a witness. Each participant received a transportation cost refund.

\section{Patient and public involvement}

Patients and/or the public were not involved in setting the research questions and in the design and implementation of the study.

\section{RESULTS}

Table 1 displays the characteristics of study participants. Overall, $81 \%$ of the participants were aged $20-49$ years; about half $(50.8 \%)$ were male; $71.2 \%$ were married and $40 \%$ had no formal education. Most key informants were male $(66.7 \%)$, with at least secondary education $(83.3 \%)$ and civil servants $(72.2 \%)$. On the other hand, slightly more than half $(51.8 \%)$ of the participants for the FGDs were female; $46.5 \%$ had no formal education and $64 \%$ were farmers.

This study exposed a range of issues regarding the perceptions of the community on the use of transport vouchers and baby kits to promote utilisation of maternal health services.We identified five broad themes: (1) 


\begin{tabular}{|c|c|c|c|}
\hline Characteristics & $\begin{array}{l}\text { FGDs } \\
n=114, n \\
(\%)\end{array}$ & $\begin{array}{l}\text { KIIs } \\
n=18, n(\%)\end{array}$ & $\begin{array}{l}\text { Total } \\
n=132, n \\
(\%)\end{array}$ \\
\hline \multicolumn{4}{|l|}{ Gender } \\
\hline Male & 55 (48.2) & $12(66.7)$ & $67(50.8)$ \\
\hline Female & 59 (51.8) & $6(33.3)$ & 65 (49.2) \\
\hline \multicolumn{4}{|l|}{ Age category } \\
\hline$<20$ years & $20(17.5)$ & $0(0)$ & $20(15.2)$ \\
\hline 20-49 years & 93 (81.6) & $14(77.8)$ & 107 (81.0) \\
\hline 50-60 years & $1(0.9)$ & 4 (22.2) & $5(3.8)$ \\
\hline \multicolumn{4}{|l|}{ Education level } \\
\hline $\begin{array}{l}\text { No formal } \\
\text { education }\end{array}$ & $53(46.5)$ & $0(0)$ & $53(40.2)$ \\
\hline Primary & $41(36.0)$ & $0(0)$ & $41(31.0)$ \\
\hline Secondary & $20(17.5)$ & 15 (83.3) & 35 (26.5) \\
\hline Tertiary & $0(0)$ & $3(16.7)$ & $3(2.3)$ \\
\hline \multicolumn{4}{|l|}{ Marital status } \\
\hline Single & $9(7.9)$ & $3(16.7)$ & $12(9.1)$ \\
\hline Married & $80(70.2)$ & $14(77.8)$ & $94(71.2)$ \\
\hline $\begin{array}{l}\text { Divorced/ } \\
\text { separated }\end{array}$ & $25(21.9)$ & $1(5.5)$ & $26(19.7)$ \\
\hline \multicolumn{4}{|l|}{ Occupation } \\
\hline Unemployed & $12(10.5)$ & $0(0)$ & $12(9.1)$ \\
\hline Farmer & $73(64.0)$ & $3(16.7)$ & $76(57.6)$ \\
\hline Petty trader & 25 (21.9) & $2(11.1)$ & $27(20.4)$ \\
\hline Civil servant & $4(3.5)$ & $13(72.2)$ & 17 (12.9) \\
\hline
\end{tabular}

FGDs, focus group discussions; KIls, key informant interviews.

context, (2) community support for the interventions, (3) health-seeking behaviours postintervention, (4) undesirable effects of the interventions and (5) implementation issues and lessons learnt. table 2 summarises the main findings under each broad theme and minor theme.

\section{Context}

Geographical inaccessibility, poor quality of health services and inadequate health facilities were perceived to be the major contextual issues affecting health service access in the district. Individuals living in remote and isolated areas had to walk long distances or use bicycles to reach health facilities. Lack of reliable means of transportation and unaffordable transportation costs exacerbated the problem of geographical inaccessibility.

...some villages are quite isolated, and the distance is very far away, and sometimes we don't have even a bicycle to send women to the health centres for help, for these reasons we feel that the interventions are extremely helpful. (Female FGD participant, HC II)
Most pregnant women who come to deliver here come from places where it is not easy to access transport. (Male key informant, HC II)

Most of the communities were served by HC IIs, which were perceived to be providing poor quality and inadequate health services due to their limited service delivery capacity.

Some sub-counties are remote with bigger populations, yet they get few health services. (Male FGD participant, HC III)

Iceme sub-county is wide with a big population without proper health services. (Male FGD participant, HC II)

\section{Community support for the interventions}

The incentive schemes were widely acceptable in the community. This was linked to their perceived positive impact and hence the desire to have them scaled-up to achieve a district-wide coverage. The schemes were perceived to be reducing maternal and newborn deaths and improving health-seeking behaviours (see below). They were also perceived to be helpful particularly to the most vulnerable and poor women, such as single mothers.

I think it [baby kit] is very useful because it is helping us. Sometimes we do not have enough money to buy these things. Mothers are happy with the basin, soap and cloth to take care of their babies. (Female key informant, Ngai Sub-County)

Single mothers will get help since the voucher facilitates delivery at the health facility. (Male FGD participant, HC II)

Besides improving maternal and newborn health, the interventions were perceived to be reducing a financial burden on families. The cost of transport to health facilities imposed a heavy financial burden on the residents leading to loss of household assets and precipitating household food insecurity, as households were forced to sell their belongings to carter for transportation costs. This mainly affected households that were poorer or located in remote and hard to reach areas.

These [the incentives] are good initiatives because they save some household food and assets like chicken or goats from being sold during the period of labour and delivery. (Male FGD participant, HC II)

Owing to the prevailing barriers to utilisation of maternal health services in the district, participants felt that the interventions should be scaled up district wide, as illustrated below.

We want to have a district-wide coverage, which can also be recognisable at the national level, not just in Ngai sub-County. Because by scaling up to other sub-counties, it will be very easy to increase delivery in the facilities, so even the district coverage will go up. (Male key informant, HC III) 
Table 2 A summary of perceptions towards incentives to promote institutional deliveries

\section{Coding tree}

1.0. Context

\subsection{Geographical inaccessibility}

1.2. Poor quality and inadequate health services

\section{Key findings}

Long distances to health facilities and remoteness of some villages. Lack of reliable means of transportation and high transportation costs.

$\mathrm{HC}$ Ils, which served a majority of the community members, were perceived to be providing poor quality and inadequate health services

\subsection{Community support for the interventions}

2.1. Acceptability and impact of the interventions

Incentives perceived to be reducing maternal and newborn deaths and improving health-seeking behaviours. Incentives also perceived to have reduced a financial burden on families, which prevented loss of household assets and household food insecurity. Interventions perceived to be helpful particularly to the most vulnerable and poor women.

2.2. The need to scale up the incentive schemes

\subsection{Preferred intervention}

The interventions need to be scaled up to cover the entire district to achieve district-wide increased utilisation of maternal health services.

Transport vouchers preferred over baby kits. However, simultaneous implementation of the two interventions was necessary given the high level of poverty and barriers to access health services in the district.

\subsection{Health-seeking behaviours postintervention}

\subsection{Increased utilisation of maternal health services}

\subsection{Bypassing resident health facilities in} favour of intervention facilities
The interventions were perceived to have increased the number of ANC attendance and institutional deliveries. The transport voucher system facilitated efficient referral of women in need of emergency obstetric care to the HC IV and the hospital.

The incentives encouraged some women in the neighbouring subcounties to by-pass health facilities in their own subcounties for services at HCs in the intervention subcounties.

Transport vouchers were perceived to have encouraged some TBAs to escort pregnant women to HCs thereby reducing the no of home deliveries.

3.3. Home deliveries and changing roles of traditional birth attendants (TBAs)

3.4. Men's involvements in maternal and newborn healthcare

\subsection{Community health awareness}

The incentives motivated men to transport their partners to health facilities for ANC and delivery and to participate in birth preparedness.

Health information and education associated with the interventions increased the community's maternal health awareness.

\subsection{Perceived undesirable effects of incentives}

4.1. Increased workload for health workers and beyond

Increased utilisation of maternal health services led to an increased workload for health workers and transporters. Concerns over the sustainability of the workloads.

4.2. Sustainability of the interventions

4.3. Encouraging 'increased fertility' Concerns about the sustainability of the interventions beyond the project period. Interventions could encourage more births. Family planning messages not included in the interventions.

Long-term use of the interventions could encourage dependency.

4.4. Encouraging dependency

5.0. Implementation issues and lessons learnt

5.1. Information gaps and consequences

Information gaps during the implementation of interventions leading to confusion, mistrust and discontent among users and transporters.

\subsection{Transport voucher design, implementation and payment issues}

Transport vouchers designed in English, yet most beneficiaries were illiterate. Uncooperative transporters who demanded immediate refunds instead of monthly refunds, delayed refunds, overcharging at night, double payments and the preferred costing method (negotiable price vs flat rate).

5.3. Insecurity and effects on transport voucher system

5.4. Poor attitudes and poor quality of care

5.5. Shortage of baby kits
Refusal by some transporters to operate at night because of insecurity. Overcharging to 'compensate' for a perceived increased insecurity risk at night.

Poor attitudes of some health workers towards transporters and women and their partners. Some community leaders lost interest in the interventions because of unfriendly behaviours of some midwives.

Shortages of baby kits. Some women had to make repeat visits to the facility to collect their kits. 
Table 2 Continued

\begin{tabular}{ll}
\hline Coding tree & Key findings \\
\hline $\begin{array}{l}\text { 5.6. Community suggestions for } \\
\text { improvement }\end{array}$ & $\begin{array}{l}\text { Community dialogues generated useful suggestions to address implementation } \\
\text { challenges. }\end{array}$ \\
\hline
\end{tabular}

ANC, antenatal care; $\mathrm{HC}$, health centre.

For us, we move around the district [for trade] and when we are in [labour]pain, maybe we are in a different sub-county, so we prefer the whole district. (Female FGD participant, HC III)

Although most of the respondents, particularly women, preferred transport vouchers over baby kits, due to poverty and the geographical inaccessibility to health facilities, simultaneous use of the two interventions was perceived to be necessary to improve the utilisation of maternal health services.

The vouchers are very helpful to us, and with baby kits, we don't have to buy the equipment. So, we need the two schemes. (Female FGD participant, HC III)

\section{Health-seeking behaviours postintervention}

The interventions were perceived to have increased the use of ANC and institutional delivery services, promoted 'bypassing' of resident health facilities in favour of intervention facilities, facilitated positive collaborations between some traditional birth attendants (TBAs) and HCs, encouraged men's involvement in maternal and newborn healthcare services, and improved community health awareness. Views regarding increased health services utilisation were expressed mainly by key informants, some of them with access to routine data.

Since the beginning of the implementation of the baby kits scheme in the facility, the number of deliveries per month has fast increased. Some of these mothers come just for ANC, but while here, they become aware that they are in labour. Moreover, some of them come without anything, so the presence of the baby kits in the facility helps them a lot. In addition, it encourages them to come to deliver here in the unit. (Male key informant, HC III)

The increased utilisation of maternal health services in the study subcounties might have resulted from the incentives themselves and from the community mobilisation that was associated with the implementation of the incentive schemes.

We have seen a real increase in the utilisation of ANC and deliveries in these facilities. Even the advocacy within the community using the VHTs, the midwives, and the peer mothers themselves has increased, so it has created awareness and knowledge that facility deliveries are best and attending antenatal care is good. (Male key informant, Member of DHMT)
The transport voucher system was perceived to have increased referrals by facilitating the transport of women to the nearest health facilities or to the referral centres for the management of pregnancy and labour-related complications.

The transport voucher is good for immediate transportation and management of pregnancy-related complications. (Male FGD participant, HC II)

In the past, they had problems to go to Anyeke HC IV, but now the coupon [transport voucher] is also helping them a lot with the referral system. (Female key informant, District Local Government)

The incentives were perceived to have encouraged some women in the neighbouring subcounties to by-pass health facilities in their resident subcounties for services at HCs in the intervention subcounties.

...we have mothers coming from the neighbouring sub-counties, like Abok. You also find someone coming from Abok leaving the HCs there and coming to Ngai here thinking she will go back with something. Maybe you could do it in all the sub-counties so that they can deliver also from there because most of them come here because of the baby kits. (Female key informant, HC III)

We know some mothers who travel from other sub-counties to come here [Acaba sub- county] because of the vouchers. If they also have the vouchers there, it will be better. (Female FGD participant, HC II)

The voucher system was perceived to have promoted positive collaboration between some TBAs and HCs resulting in a reduction in home deliveries. Following dialogues with some community leaders and health workers, some TBAs were happy to receive incentives and in return refer and escort pregnant women to HCs for childbirth instead of assisting them to deliver at home.

With this programme, even some TBAs are escorting pregnant mothers to the health centre. (Female FGD participant, HC II)

Transport vouchers motivated men to transport or escort their wives to health facilities for ANC and delivery, and to participate in birth preparedness.

The voucher system has encouraged husbands to transport their wives to the nearest HCs for ANC 
and delivery.' (Male FGD participant, Abere Trading Centre)

They [interventions] motivate couples from the period of conception to delivery to actively seek health services. (Male FGD participant, HC II)

Health information and education messages associated with the baby kits and transport voucher schemes sensitised the communities and improved community health awareness beyond improving the use of facility delivery services.

...the educative message they receive from there [HCs] will make them understand the importance of bringing mothers to the health facility. It is mainly important for men. Secondly, they spread the message about what they received to the community. (Male key informant, Myene Sub-County)

\section{Perceived undesirable effects of the incentives}

Perceived undesirable effects of the schemes included increased workload for health workers and beyond, sustainability of the interventions, encouraging 'increased fertility', and encouraging dependency. Unlike the other views, these views were expressed exclusively by key informants. The interventions were perceived to have increased utilisation of maternal health services as well as the workload of transporters and health workers. Whereas this was a good effect for transporters, it was perceived to have led to overwork and stress among health workers. To cope with the situation, it was suggested that the number of staff working in the facilities implementing the interventions should be increased.

We need an additional midwife and regular supplies to meet the workload. (Female key informant, HC II)

In terms of human resources, the [number of] health staff is not enough; it makes an overwork. The workload has increased, giving stress. The midwives in those health facilities are working alone, and current workloads are not sustainable. (Male key informant, Member of DHMT)

There were concerns about the sustainability of the interventions and their effects beyond the funding period.

The biggest challenge for me is the issue of sustainability. We are dealing with vulnerable and poor people, and we are giving it like a handout; so, the greatest challenge is the issue of sustainability. When the programme stops, are we able to sustain it? (Male key informant, Member of DHMT)

The bad part is the sustainability because when people are used to certain things, when they are used to gifts, you need to maintain it. (Male key informant, HC III)

Considering the low family planning uptake and the high fertility rate in the district, some leaders were concerned that the interventions could increase fertility.
You know how much we have advocated for family planning, but it is still the second-lowest activity in the district, so the rate of reproduction is too high. (Female key informant, District Local Government)

...the family planning messages are not included in the intervention because sometime this intervention could be a motivating factor to produce more children. (Male key informant, Loro Sub-County)

Although the interventions were considered useful in the short term, there were concerns that long-term implementation would encourage dependency in the community.

It is a useful system, but if the initiative continues the community will become too much dependent on NGOs. I think it should be stopped after some time because it will encourage dependency among our community. (Male key informant, Myene Sub-County)

Improving the socioeconomic status of the community, for example, by setting up income generating activities for women, was a potential solution to dependency.

I think that after delivering, women should be encouraged to have another source of income to take care of the baby so that in caseincentives will not be there, they will be able to go to the facility even without vouchers. (Male key informant, Loro Sub-County)

\section{Implementation issues and lessons learnt}

Several issues emerged with the implementation of the interventions. They included: information gaps and consequences, transport voucher design, implementation and payment, poor attitudes and poor quality of care, insecurity and its effects on transport voucher system and shortage of baby kits. The community suggested ways to improve the implementation of the schemes.

Information gaps, mainly at the start of the interventions, led to undesirable consequences such as confusion, mistrust and discontent, principally related to payment of the transporters.

Two transporters of Akaoidebe village were not paid for two times after transporting pregnant mothers to deliver at Ngai HC. One of the transporters was told the money was only paid to transporters who use motorbikes to transport mothers, not bicycles, and the other transporter was told that he delayed and so the organisation took back the money. All major complains are on staff attitudes: bad language and refusal to pay money. (Male FGD participant, Abere Trading Centre)

The staff concerned with the payment of the vouchers are reluctant to pay the transporters even after the time expected has passed. (Male FGD participant, HC III)

The implementation of the transport voucher system was associated with several issues, primarily about the 
amount of money to be paid and the timing of refunds. The vouchers were designed in English, but most beneficiaries could not read English. Some transporters were uncooperative and demanded immediate refunds instead of monthly refunds according to the voucher system guidelines. Other issues included delayed voucher refunds, overcharging at night, double payments and the preferred method to determine the cost (ie, a negotiable amount vs a flat amount).

From my experience with the local community, the main challenge that we are facing is the management of the money for the refund. Some men who transport patients [pregnant women and mothers] here ask for money immediately even before we have seen the patient, or they ask for money while you are working with other patients, and they do not like to wait. (Male key informant, HC II)

Sometimes the transporters are paid twice due to lack of awareness. Some boda bodas ask mothers to pay for fuel to be transported to the health unit and later sign for the voucher refund at the HC. (Male FGD participant, HC II)

Inadequate sensitisation, miscommunication and poor health worker attitudes often resulted in poor quality of care.

Some women fear to attend ANC and delivery at the facility because of the aggressive character and unwelcome attitudes of some midwives. The issues with the voucher system have been abandoned by some community members because of the bad attitudes and language used against men and women by the health workers. (Male FGD participant, Abere Trade Centre)

Staff, especially health centre midwives should be trained on how to handle mothers and transporters because there are complaints of harsh treatment. (Male FGD participant, HC III)

Some transporters refused to operate at night because of insecurity. Alternatively, the transporter would overcharge women to 'compensate' for the perceived increased insecurity risk at night.

Some boda bodas don't like to come to our villages in the night because they are afraid of robbers. (Female FGD participant, HC II)

Transporters overcharge mothers, especially at night, when labour occurs. (Male FGD participant, HC III)

Increased facility deliveries led to shortages of baby kits and some women had to make repeat visits to the facility to collect their kits.

For the challenges, let me start from the baby kits. The rate of reproduction is too high, so the demand is still too high, and those things are there, but you find it is not enough. (Female key informant, District Local Government)

Sometimes the midwives tell us that the kits are finished so we have to come and collect them when they bring more. (Female FGD participant, HC III)

Community dialogues provided platforms for open discussions to address implementation challenges such as information gaps, regulation, selection of transporters and adherence to the voucher system guidelines, voucher refund and personal conduct.

A copy [records] of the baby kits supplied should be available to the sub-county to guarantee easy monitoring and supervision. (Male key informant, Ngai Sub-County)

There should be a clear separation between mothers who pay their transporters immediately and those unable to pay immediately. Mothers who negotiate and pay their transporters before reaching the health facility should later sign for the transport refund to avoid double payment. (Male FGD participant, Abere Trade Centre)

A copy of the voucher given to the person escorting the mother should be translated into Luo [Lango] language for easy and better understanding. (Male FGD participant, Abere Trading Centre)

\section{DISCUSSION}

We examined community perceptions on the use of baby kits and transport vouchers to improve the utilisation of facility-based delivery services in Oyam district. Generally, participants perceived the interventions to be improving the utilisation of maternal health services through addressing major barriers such as geographical inaccessibility to health facilities and delays in transferring obstetric emergencies from the lower level health facilities to the higher levels of care.

Distance to health facilities is known to be inversely associated with the utilisation of skilled birth care in SSA. ${ }^{28}$ Given the high poverty levels in the district, the cost of transport frequently emerged as a barrier to accessing health services. This is consistent with what has been reported in a recent review on barriers to obstetric care access in SSA. ${ }^{29}$ In many rural settings, considerable delays in reaching health facilities have resulted in avoidable maternal deaths. ${ }^{28}$ The schemes were also seen to be very helpful to the most vulnerable and disadvantaged groups such as single mothers. ${ }^{30}$ These findings are consistent with those of the quantitative study that evaluated the effects of the incentives. ${ }^{23}$ Notwithstanding, this study provides further insights into the pathways through which the interventions helped to achieve the effects that is, through changing the role of TBAs, the involvement of men in maternal health issues, and community involvements in the interventions. We also elaborate on 
the community concerns related to the perceived negative impacts of the interventions.

The voucher system promoted unexpected collaborations between some TBAs and formal health workers. The TBAs who referred and escorted pregnant women to deliver at the health facilities implementing the voucher system were recognised as 'transporters' and received voucher refunds. This collaboration might have contributed to reduced home deliveries. Studies show that TBAs can change their role from attending to home births to promoting institutional childbirth if given the right incentives, training and a conducive working environment. ${ }^{11-34}$ Thus, there is a great potential to achieve higher utilisation of maternal health services in this context through the appropriate involvement of TBAs.

Community health awareness of maternal health issues was perceived to have improved during the implementation of the incentive schemes. The implementation of the incentive schemes was associated with community sensitisation and mobilisation using diverse strategies, individuals and community structures. These included community dialogues, local radio broadcasts, health facilities and health workers, VHT members, transporters and peer mothers. In both the FGDs and KIIs, respondents said that there had been behavioural changes such as men escorting their wives to the HCs for antenatal and delivery services, which was uncommon before the interventions. Thus, the various forms of community involvements may explain the perceived improvements in maternal health awareness and perceived behavioural changes over a relatively short period.

By improving the utilisation of maternal health services, the interventions also increased workloads for transporters, health workers, social workers and VHT members. Even though transporters experienced an increased workload, which translated into more economic gains, some villages had a shortage of transporters, especially at night. Among health workers, midwives were the most affected, as no additional staffs were recruited during the project. In line with our findings, a review has pointed out that demand-side incentive schemes can improve the utilisation of maternal healthcare services but there is a need to simultaneously strengthen the supply side to achieve the desired outcomes. ${ }^{5}$

Given the concerns of some community leaders regarding sustainability of the interventions beyond the funded period, CUAMM (the implementing non-governmental organisation (NGO)) initiated dialogues with the district local government, health authorities and community leaders to explore ways of mitigating some of the potential untoward effects of the interventions. ${ }^{14}$ Furthermore, the organisation commissioned a study to investigate the feasibility of setting up a community health insurance scheme that could support the transport voucher scheme in the district. ${ }^{35}$

Oyam district has high poverty and fertility levels with low uptake of family planning services. Consequently, some key informants were concerned that the interventions could increase fertility. A survey conducted in conflict-affected areas of Sudan, Northern Uganda and the Democratic Republic of Congo found low knowledge and use of family planning services. Major barriers to family planning use included health system inadequacies, fear of side effects of the methods and insecurity. As a postconflict setting with high maternal, newborn and child deaths, ${ }^{19}$ the desire for large family sizes in Oyam is understandable. Therefore, improving maternal and child survival can sustain the demand for family planning services in the district. ${ }^{36-39}$ Although, the incentive schemes were not vertical interventions that needed separate family planning promotion, concerted efforts to strengthen family planning services across the district may resolve the low uptake of family planning services.

There were also concerns that long-term implementation of the interventions could encourage dependency in the communities. In 2013, the district reported a maternal mortality ratio of 500/100 000 live births, which was one of the highest in the country. Moreover, the district is under-resourced and depends regularly on donors to provide basic services. ${ }^{19}$ Therefore, donor-supported interventions such as the incentive schemes, which may improve utilisation of maternal health services and reduce maternal and newborn deaths may continue to be a 'necessary evil' until such a time when the district can afford to provide adequate services to improve its health indicators.

Community dialogues were crucial in dealing with a wide range of issues related to the implementation of the schemes. Information gaps led to inadequate sensitisation and miscommunication while poor attitudes of some health workers resulted in a poor quality of care. Of all these concerns, poor health worker attitudes were the most lamented about. Studies show that fear of being maltreated by health workers constitutes a barrier to using facility delivery services. ${ }^{240}$ In some communities, health workers were perceived as obstacles to the smooth implementation of the incentive schemes. Hence, it may not be surprising that some community leaders lost interest in the interventions out of frustration.

Nonetheless, as community involvement gradually strengthened, it encouraged ownership and resulted in communities taking on more direct roles in the regulation and implementation of the voucher system, as has also happened elsewhere. ${ }^{12-14}$ For example, some villages selected and registered their transporters who were willing to operate within the existing transport voucher guidelines. Because transporters played a central role in the voucher system, many of the implementation issues revolved around them. Hence, having the communities regulating their transporters was a vital achievement that addressed several key issues in operating the voucher system. Community dialogues also provided suggestions to improve the design of the transport voucher system and to phase out baby kits and replace them with vouchers, which were found to be more useful and less costly. 


\section{Strengths and limitations}

The FGDs and KIIs engaged different categories of study participants and collected a wide range of perceptions to ensure a cross-sectional representation of viewpoints. Triangulation of the results from different categories of respondents and data collection methods and the use of two coders to analyse the data increases the validity and reliability of our findings. FGDs were conducted mainly in HCs, which might have restricted the freedom of expression. To mitigate this problem, all the discussions were performed in a quiet and closed room in the absence of any health facility staff. Participants were assured of confidentiality and were encouraged to freely express themselves without fear of victimisation or future prejudice. Despite these precautionary measures, it is possible that some of the participants might have been reluctant to voice negative aspects of the intervention as staff members of the NGO that implemented the intervention and funded the study, carried out the data collection while the intervention was ongoing. In addition, some information might have been lost during note taking for the few FGD and KII sessions that were not audio recorded.

Even though we made efforts to achieve a gender-balanced representation for the KIIs, this was not possible as most key informants were male. Additionally, even though there were more female participants than males in the FGDs, analysis of the viewpoints that we captured show male dominance. This observation may be reflective of the largely male-dominated society where the study was conducted. This situation might have led to potential biases in some of the perceptions elicited. Furthermore, increasing the utilisation of health services in a health resource-limited setting such as Oyam may not necessarily lead to improved maternal and newborn health outcomes, particularly if the quality of care is substandard ${ }^{41}$ Finally, this study could have benefited from the views of TBAs concerning the influence of the schemes on their roles. Information on their changed role emerged mainly from mothers and key informants.

\section{CONCLUSIONS}

This study provides further insights into the implementation of incentive schemes to improve maternal health services utilisation in Uganda. For a successful implementation of similar interventions, we recommend the active involvement of the beneficiary communities and stakeholders throughout the design and implementation of the schemes. Moreover, working with beneficiaries and stakeholders can mitigate potentially undesirable effects of such schemes. The findings of this study are relevant for planning and implementing similar schemes in low-income countries.

Author affiliations

${ }^{1}$ Doctors with Africa CUAMM, Aber Hospital, Lira, Uganda
${ }^{2}$ Maternal and Child Wellbeing Unit, African Population and Health Research Center, Nairobi, Kenya

${ }^{3}$ Division of Epidemiology and Prevention, National Cancer Center Japan, Chuo-ku, Japan

${ }^{4}$ School of Economics and Development, University of Florence, Florence, Italy

${ }^{5}$ District Health Office, Oyam District Local Government, Loro, Uganda

${ }^{6}$ Doctors with Africa CUAMM, Kampala, Uganda

${ }^{7}$ Operational Research Unit, Doctors with Africa CUAMM, Padua, Italy

Correction notice This article has been corrected since it was published. The article title has been updated.

Acknowledgements We thank Jackie Kwecwiny (social worker), Anthony Opio (social worker) and Christopher Bingom (data clerk) for their roles in obtaining informed consents from study participants, facilitating the focus group discussions and helping during interviews. We are grateful to Sarah Awor (district biostatistician) for providing us with data and inputs from the district office.

Contributors WM conceived and designed the study, contributed to the data collection, participated in the data analysis, drafted the manuscript and participated in the interpretation of the findings and revision of the manuscript. CW drafted the abstract, reviewed the Methods section, contributed to the data analysis, interpretation of the findings and revision of the manuscript. EDV, MN, JBO and SA contributed to the data collection, interpretation of findings and revision of the manuscript. CA participated in the editing of the manuscript and interpretation of findings. PL and GP contributed to the interpretation of the findings and revision of the manuscript. All authors read and approved the final version of the manuscript.

Funding This study was funded by Doctors with Africa CUAMM, Italy.

Disclaimer The views expressed in this document are solely the responsibility of the authors and do not necessarily represent the views of Doctors with Africa CUAMM.

Competing interests $\mathrm{CW}, \mathrm{MN}, \mathrm{CA}, \mathrm{JB} 0$ and $\mathrm{SA}$ have no competing interests to declare. At the time of this study, WM, EDV, PL and GP were employees of Doctors with Africa CUAMM.

Patient consent for publication Not required.

Ethics approval This study was approved by Lacor Hospital Research and Ethical Review Committee and registered by the Uganda National Council for Science and Technology (UNCST filed Ref \#: SS 4252). The study was also approved by the local authorities in Oyam district.

Provenance and peer review Not commissioned; externally peer reviewed.

Data availability statement Data are available on reasonable request.

Open access This is an open access article distributed in accordance with the Creative Commons Attribution Non Commercial (CC BY-NC 4.0) license, which permits others to distribute, remix, adapt, build upon this work non-commercially, and license their derivative works on different terms, provided the original work is properly cited, appropriate credit is given, any changes made indicated, and the use is non-commercial. See: http://creativecommons.org/licenses/by-nc/4.0/.

\section{REFERENCES}

1. WHO, The World Bank. Tracking universal health coverage: first global monitoring report. Geneva; 2015. http://www.who.int/ healthinfo/universal_health_coverage/report/2015/en

2. WHO, UNICEF. A decade of tracking progress for maternal, newborn and child survival: the 2015 report. Geneva WHO; 2015. http:// countdown2015mnch.org/documents/2015Report/Countdown_to_ 2015_final_report.pdf

3. UNICEF. Maternal health current status and update: antenatal care, 2017. Available: https://data.unicef.org/topic/maternal-health/ antenatal-care/\#

4. WHO. Skilled attendance at birth: situation and trends, 2017. Available: http://www.who.int/gho/maternal_health/skilled_care/ skilled_birth_attendance_text/en/ [Accessed 15 Dec 2017].

5. Murray SF, Hunter BM, Bisht R, et al. Effects of demand-side financing on utilisation, experiences and outcomes of maternity care in low- and middle-income countries: a systematic review. BMC Pregnancy Childbirth 2014;14:30.

6. Ir P, Horemans D, Souk N, et al. Using targeted vouchers and health equity funds to improve access to skilled birth attendants for poor women: a case study in three rural health districts in Cambodia. BMC Pregnancy Childbirth 2010;10:1. 
7. Gopalan SS, Durairaj V. Addressing maternal healthcare through demand side financial incentives: experience of Janani Suraksha Yojana program in India. BMC Health Serv Res 2012;12:319.

8. Bellows B, Kyobutungi C, Mutua MK, et al. Increase in facility-based deliveries associated with a maternal health voucher programme in informal settlements in Nairobi, Kenya. Health Policy Plan 2013;28:134-42.

9. Ekirapa-Kiracho E, Waiswa P, Rahman $\mathrm{MH}$, et al. Increasing access to institutional deliveries using demand and supply side incentives: early results from a quasi-experimental study. BMC Int Health Hum Rights 2011;11 Suppl 1:S11.

10. Obare F, Warren C, Abuya T, et al. Assessing the population-level impact of vouchers on access to health facility delivery for women in Kenya. Soc Sci Med 2014;102:183-9.

11. Wilunda $C$, Scanagatta $C$, Putoto $G$, et al. Barriers to institutional childbirth in Rumbek North County, South Sudan: a qualitative study. PLoS One 2016;11:e0168083.

12. Ekirapa-Kiracho E, Namazzi G, Tetui M, et al. Unlocking community capabilities for improving maternal and newborn health: participatory action research to improve birth preparedness, health facility access, and newborn care in rural Uganda. BMC Health Serv Res 2016;16(Suppl 7):638.

13. Howard-Grabman L, Miltenburg AS, Marston C, et al. Factors affecting effective community participation in maternal and newborn health programme planning, implementation and quality of care interventions. BMC Pregnancy Childbirth 2017;17:268.

14. Katahoire AR, Henriksson DK, Ssegujja E, et al. Improving child survival through a district management strengthening and community empowerment intervention: early implementation experiences from Uganda. BMC Public Health 2015;15:797.

15. Austin-Evelyn K, Sacks E, Atuyambe L, et al. The promise of Mama kits: perceptions of in-kind goods as incentives for facility deliveries in Uganda. Glob Public Health 2017;12:565-78.

16. Okal J, Kanya L, Obare F, et al. An assessment of opportunities and challenges for public sector involvement in the maternal health voucher program in Uganda. Health Res Policy Syst 2013;11.

17. Uganda Bureau of Statistics (UBoS). National population and housing census: census 2014 final results. Kampala UBOS; 2017. http://www.ubos.org/?s=Final+Results

18. Uganda Bureau of Statistics and ICF. Uganda demographic and health survey 2016. Kampala, Uganda and Rockville, Maryland, USA UBOS and ICF; 2018.

19. Republic of Uganda. Oyam district local government statistical Abstract 2012/13. Kampala Republic of Uganda; 2014. http://www. ubos.org/statistical-activities/community-systems/district-profiling/ district-profilling-and-administrative-records/

20. Fisseha G, Berhane $\mathrm{Y}$, Worku A, et al. Distance from health facility and mothers' perception of quality related to skilled delivery service utilization in northern Ethiopia. Int J Womens Health 2017;9:749-56.

21. Pfeiffer C, Mwaipopo R. Delivering at home or in a health facility? health-seeking behaviour of women and the role of traditional birth attendants in Tanzania. BMC Pregnancy Childbirth 2013;13:55.

22. Titaley CR, Hunter CL, Dibley MJ, et al. Why do some women still prefer traditional birth attendants and home delivery?: a qualitative study on delivery care services in West Java Province, Indonesia. BMC Pregnancy Childbirth 2010;10:43.

23. Massavon W, Wilunda $C$, Nannini M, et al. Effects of demand-side incentives in improving the utilisation of delivery services in Oyam district in northern Uganda: a quasi-experimental study. BMC Pregnancy Childbirth 2017;17:431.

24. Anastasi E, Borchert M, Campbell OMR, et al. Losing women along the path to safe motherhood: why is there such a gap between women's use of antenatal care and skilled birth attendance? a mixed methods study in northern Uganda. BMC Pregnancy Childbirth 2015; $15: 287$.

25. Tong A, Sainsbury P, Craig J. Consolidated criteria for reporting qualitative research (COREQ): a 32-item checklist for interviews and focus groups. Int J Qual Health Care 2007;19:349-57.

26. Dawson S, Manderson L, Tallo VL. A manual for the use of focus groups. Boston, MA, USA: by international nutrition foundation for developing countries 1993.

27. Gläser J, Laudel G. Life with and without coding: two methods for early-stage data analysis in qualitative research aiming at causal explanations. Forum Qualitative Sozialforschung 2013;14.

28. Wong KLM, Benova L, Campbell OMR. A look back on how far to walk: systematic review and meta-analysis of physical access to skilled care for childbirth in sub-Saharan Africa. PLoS One 2017;12:e0184432.

29. Kyei-Nimakoh M, Carolan-Olah M, McCann TV. Access barriers to obstetric care at health facilities in sub-Saharan Africa-a systematic review. Syst Rev 2017;6:110.

30. Kiwanuka SN, Ekirapa EK, Peterson S, et al. Access to and utilisation of health services for the poor in Uganda: a systematic review of available evidence. Trans R Soc Trop Med Hyg 2008;102:1067-74.

31. Rudrum S. Traditional birth attendants in rural Northern Uganda: policy, practice, and ethics. Health Care Women Int 2016;37:250-69.

32. Wilunda C, Dall'Oglio G, Scanagatta C, et al. Changing the role of traditional birth attendants in Yirol West County, South Sudan. PLoS One 2017;12:e0185726.

33. Pyone T, Adaji S, Madaj B, et al. Changing the role of the traditional birth attendant in Somaliland. Int J Gynaecol Obstet 2014;127:41-6.

34. Kyomuhendo GB. Low use of rural maternity services in Uganda: impact of women's status, traditional beliefs and limited resources. Reprod Health Matters 2003;11:16-26.

35. Biggeri M, Nannini M, Putoto G. Assessing the feasibility of community health insurance in Uganda: a mixed-methods exploratory analysis. Soc Sci Med 2018;200:145-55.

36. McGinn T, Austin J, Anfinson K, et al. Family planning in conflict: results of cross-sectional baseline surveys in three African countries. Confl Health 2011:5:11.

37. Ouma S, Turyasima M, Acca $\mathrm{H}$, et al. Obstacles to family planning use among rural women in Atiak health center IV, Amuru district, Northern Uganda. East Afr Med J 2015;92:394-400.

38. Orach CG, Otim G, Aporomon JF, et al. Perceptions, attitude and use of family planning services in post conflict Gulu district, Northern Uganda. Confl Health 2015;9:24.

39. Elmusharaf K, Byrne E, O'Donovan D. Social and traditional practices and their implications for family planning: a participatory ethnographic study in Renk, South Sudan. Reprod Health 2017;14:10

40. Kwagala B. Birthing choices among the Sabiny of Uganda. Cult Health Sex 2013;15 Suppl 3:S401-S414.

41. Souza JP, Gülmezoglu AM, Vogel J, et al. Moving beyond essential interventions for reduction of maternal mortality (the who multicountry survey on maternal and newborn health): a crosssectional study. Lancet 2013;381:1747-55. 